\title{
Fostering Regional Integration in Africa: Lessons from Manantali Energy Project (Mauritania, Mali \& Senegal)
}

\author{
Albert-Enéas Gakusi ${ }^{1}$, Laura Delponte ${ }^{2}$, Samson K. Houetohossou ${ }^{1}$ \\ ${ }^{1}$ Independent Development Evaluation (IDEV), African Development Bank, Abidjan, Côte d'Ivoire \\ ${ }^{2}$ Department of Economics, Management and Quantitative Methods, Milan University, Milan, Italy \\ Email: a.gakusi@afdb.org, laura.delponte@unimi.it, s.houetohossou@afdb.org
}

Received 11 January 2015; accepted 8 March 2015; published 13 March 2015

Copyright (C) 2015 by authors and Scientific Research Publishing Inc.

This work is licensed under the Creative Commons Attribution International License (CC BY). http://creativecommons.org/licenses/by/4.0/

(c) (i) Open Access

\begin{abstract}
Regionalism has been a long-standing objective of international development assistance at least since the 1960s. However it is only since the early 2000s that international organizations have significantly increased their assistance to operations designed to foster regional integration as a means to achieve tangible national and regional development goals. These operations address challenges that are common to a group of countries and whose resolution is essentially beyond national responsibilities and capabilities. Existing evidence suggests that financing arrangements, coordination of integration operations, and sustaining their results represent a challenge and requires strong political commitment as well as proactive and effective governance to overcome collective disincentives to cooperate. The country demand for a regional operation needs to be based on an extensive preparation that provides a sound analysis of the rationale, the political economy and the costs and benefits of the operation. This paper aims to illustrate challengescoordination failure, free-riding problem, cost-benefit estimation-standing in the way of integration projects and how they were dealt with in the case of Manantali energy project, considered as a successful integration project. Lessons for future projects are drawn from the case.
\end{abstract}

\section{Keywords}

Regional Integration, Effectiveness, Efficiency, Impacts, Sustainability, Coordination

\section{Introduction}

This paper aims at assessing the extent to which the Manantali energy project was relevant to fostering regional

How to cite this paper: Gakusi, A.-E., Delponte, L. and Houetohossou, S.K. (2015) Fostering Regional Integration in Africa: Lessons from Manantali Energy Project (Mauritania, Mali \& Senegal). Open Journal of Social Sciences, 3, 91-102. 
cooperation and integration. It explores if the expected benefits have materialized and to what extent they have been produced in an efficient way. It finally assesses if the project's benefits are sustainable and equitably shared. The paper also looks at the performance of the African Development Bank (the Bank thereafter) and seeks to understand the factors leading to success or failure. It also draws lessons that can be useful for similar projects.

The Manantali hydropower project involves cross-border cooperation of Senegal, Mali and Mauritania under the egis of the Organisation pour la Mise en Valeur du fleuve Sénégal (Senegal River Basin Development Authority or OMVS), a regional river basin organization. It established a unique sub-regional power system including a 200 MW hydroelectric plant at the foot of the Manantali dam, a 1000-kilometer long system of $225 \mathrm{kV}$ transmission lines and sub-stations that distribute electricity produced to the main load centers in Mali, Mauritania and Senegal, both operated in real time by a central load dispatching system located at Manantali. As part of the Manantali hydropower project, to address the adverse impact of the dam and establish a shared framework for water management, donors agreed to establish an Environmental Impact Mitigation and Monitoring Program (PASIE) [1].

The paper is based on a critical analysis of the vast documentation available, including internal project appraisal, evaluations carried out by other donors and energy project comparative studies, as well as on results of interviews, and focus group discussion with the project's stakeholders in September 2011 in Mali, Senegal and Mauritania. Compared with previous evaluations, this evaluation is more focused on the project's institutional and organizational framework as a possible model for multinational operations.

\section{Context, Development and Governance}

\subsection{The Sub-Regional Energy Sector and the Need for Increased Hydroelectricity}

At the time the project was initiated, the power sectors of the three countries were facing severe power shortages coupled with an increased cost for electricity production that was predominantly of thermal origin. Power development was based on small scale and inefficient generation technologies. Oil had to be imported from abroad at highly volatile international prices. Although electricity production has increased over the years, it still falls short to meet the current and estimated needs, given the increasing demand driven by urbanization, growth in per capita GDP and increasing demographic trend [2].

Power production and distribution is dominated by three state-owned companies: SENELEC (Senegal), SOMELEC (Mauritania) and EDM (Mali). All companies face severe budget constraints, insufficient cost recovering ratio and are heavily subsidized. At present, lack of sufficient and reliable energy supply results in very low electrification rate, frequent power outages, especially in Senegal, and uncompetitive production costs. The precarious financial situation of the national electricity companies urges the three countries toward fully exploiting the hydroelectric potential of the Senegal River [2].

The Senegal River Basin has an estimated hydropower potential of 1200 MW of which only 200 MW has so far been developed thanks to the Manantali hydropower project. In addition to that of Guinea, a recent member of the OMVS, has an estimated potential of $6000 \mathrm{MW}$, which can generate around 26 TWh per year of electricity at relatively low cost [3]. It may be recalled that Guinea was a founder member of the OMVS predecessor organization, Organisation des Etats Riverains du Fleuve Sénégal, which dissolved because of political tensions. This hydropower potential remains largely untapped and requires huge financing to be developed.

\subsection{Project Objectives and Description}

The project of building a dam and an hydropower plant at Manantali was devised in the 1970s. With significant contribution from the Bank and other donors, the Manantali dam was completed in 1987, along with another dam at Diama in the lower Senegal river's delta. The construction of the power plant was not pursued at that time because of insufficient financing, disagreement on the route of the transmission lines, outbreak of a conflict between Mauritania and Senegal between 1988 and 1989, and the low price of oil. An agreement between the three participating countries was reached in 1996 and several donors offered loans to finance the construction of the hydropower plant and transmission facilities [4]. The objectives are presented in the Box 1.

Total project cost was estimated at appraisal at 209.9 billion FCFA. Ten donors offered their support, namely the French Development Agency (AFD), the World Bank, Kredistanstadt fur Wiederaufbau (KfW, Germany), the Canadian International Development Agency (CDA), the European Union, the European Investment Bank 
(EIB), the Islamic Development Bank (IDB), the African Development Bank (AfDB), Arab Fund for Economic and Social Development (FADES), the West African Development Bank (BOAD) and other small financers. AfDB's contribution to the project, which was directed to finance the construction of the Western transmission lines, amounted to a loan of 25 million UA, which corresponded to nearly $9 \%$ of the project [4].

\subsection{Institutional Arrangements}

The project governance structure. OMVS is a sub-regional water basin organization established in 1972 by the governments of Mauritania, Mali and Senegal to jointly exploit the water resources of the Senegal River and make them less vulnerable to rainfall deficits. Its mandate is limited to cooperation on managing the river resources in the sector of agriculture (irrigation), transport (navigation) and energy (hydroelectricity), whereas other more ambitious aspects of regional integration, such as trade agreements were ruled out. In 2006, Guinea, where most Senegal River tributaries originate, officially joined the organization. The OMVS has a four-tier structure (Figure 1).

Upon donor request, the Société de Gestion du Barrage de Manantali (SOGEM) was created by the OMVS to be the asset owner and operator of Manantali. The Société de Gestion du Barrage de Diama (SOGED), a sister organization of SOGEM, was also established to manage the Diama dam and collect irrigation fees. In turn, SOGEM contracted Eskom Energie Manantali (EEM), a subsidiary of the Southern African utility company ESKOM, to manage the hydropower station and the associated infrastructure. The Comité Technique Permanent

\section{Box 1. Objectives of the Manantali hydroelectric power.}

- Reduce the long-term cost of electricity supply,

- Contribute to meeting debt service associated with the building of the Manantali dam,

- Contribute to increasing the efficiency and reliability of the power systems,

- Establish an effective organization to construct and operate the project facilities and to mitigate environment and health impacts of the Manantali dam,

- Promote competitive private sector participation in project operation and in financing of future generation projects in the Senegal River Basin,

- Support the traditional agricultural sector downstream through rational management of the Manantali reservoir.

AfDB (2007), Rapport d'achèvement de projet, non présenté au Conseil d’Administration.

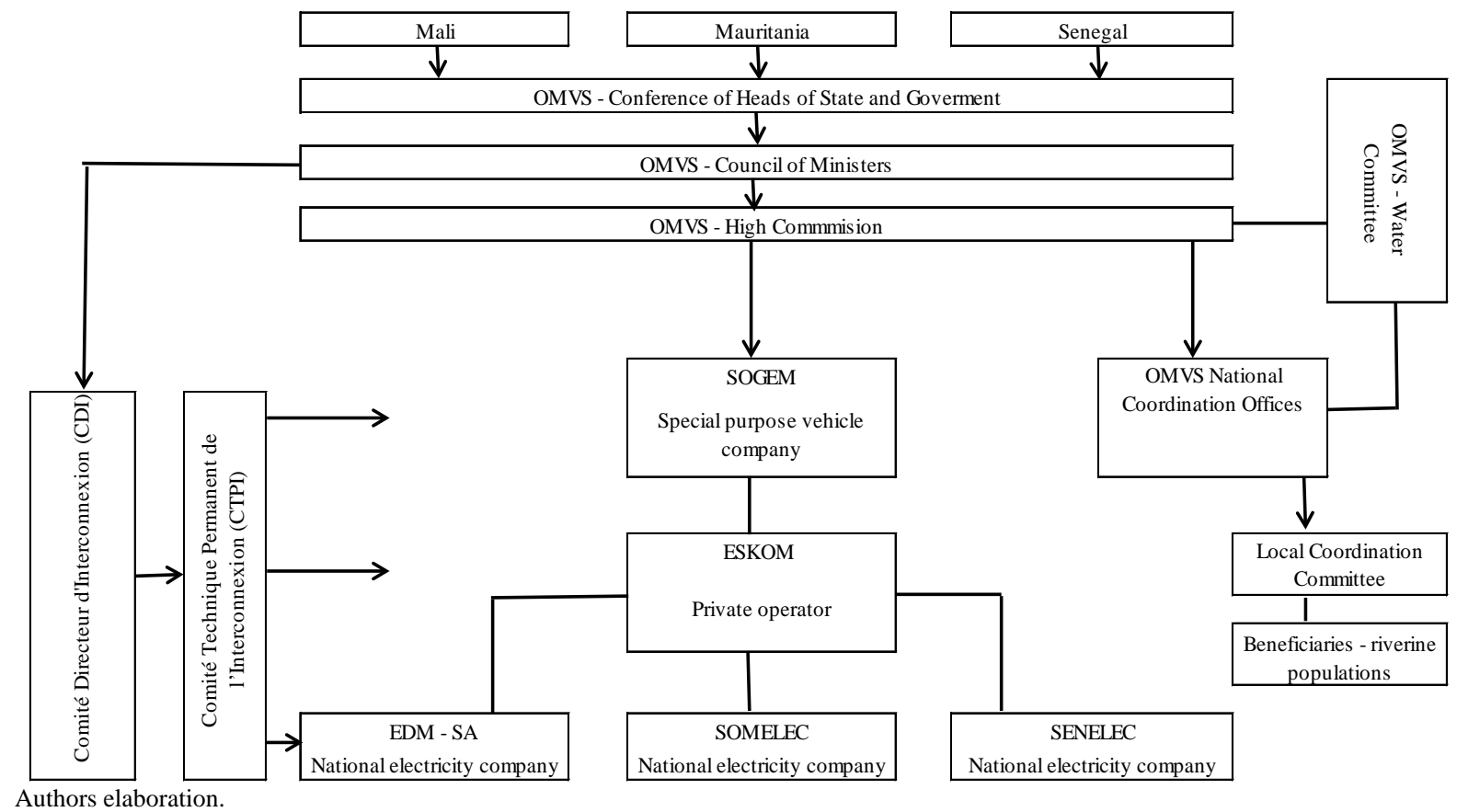

Figure 1. Project institutional setting. 
de l'Interconnexion (CTPI), which is made up of representatives from SOGEM; EEM and the three national electricity companies, is the body responsible to define rules and procedures for power generation. Its activities are guided by the Comité Directeur de l'Interconnexion (CDI) which is composed of senior staff from the three above mentioned bodies [5].

Project implementation was based on the Special Purpose Company (SPC) model, which entails that the entire project is held under the unified ownership of an SPC whose asset ownership is in turn held by the participating countries (Box 2).

Institutional agreements. The ownership of the infrastructure, cost allocations and rules for water usage are governed by the Convention concerning the legal status of jointly owned infrastructures (1978) and the Convention concerning the financing of jointly owned structures (1982). These establish that the Diama and Manantali dams are owned by the member states through their shareholding in SOGEM [6].

A water charter was signed later in 2002 to improve management of the Manantali Reservoir and enable the OMVS better address the negative environmental and social impacts of the two dams. It also guides implementation of the ongoing Senegal River Basin Multi-purpose Water Resources Development Project (PGIRE), which is run by the OMVS with World Bank support.

The cost/benefit sharing methodology, which was contracted out to Utah State University, is based on the "adjusted separable cost remaining benefit" method. Benefits were analyzed in three categories including irrigation, energy production and navigation, and subsequently divided among the participating countries following fixed quotas, known as "the key" (Table 1). Over the years, the key was readjusted, but the council never formally adopted a new distribution of the OMVS projects' costs and benefits [2].

The approach followed ensured an equitable and consensual benefit sharing among the three countries. In particular, consensual means that each member state has equal rights in the decision making process under the Convention, whereas equity refers to the entitlement of each country to benefit from the river. This was quite unique amongst contemporary river basin organization practices which tended to base discussions on water allocations rather than over benefits derived from water use [6].

Manantali management contract. The contractual relationship between member states, SOGEM and the national electricity companies is governed by the OMVS Interconnected Network Tariff Protocol which states that national electricity companies undertake to consume and pay the electricity generated by Manantali and that electricity is to be delivered in the agreed quotas. In addition, there is an Interconnection Protocol that defines the technical framework for power generation, and supply contracts between EEM and the three national utilities.

EEM is responsible for collecting payments from national electricity companies and to transfer the revenues to SOGEM less EEM's contract fee. The relationship between EEM and the national electricity companies is established by an annual power generation plan, while energy needs are communicated weekly. The electricity

Box 2. Advantages of the SPC model as compared to the traditional project Implementation unit include.

- Overcoming the disconnect between the allocation of project costs and the distribution of project benefits,

- Streamlined and cheaper project coordination,

- Centrally managed operation and maintenance,

- Share of interests and priorities,

- Prevailing regional interests over local needs,

- Consistent and unified system of usage charges.

AfDB (2011) [3].

Table 1. Breakdown of OMVS projects' costs and benefits (\%).

\begin{tabular}{ccccc}
\hline Country & Costs & Irrigation potential & Energy & Navigation \\
\hline Mali & 35.3 & Approx. 0 & 52 & 88 \\
Mauritania & 22.6 & 31 & 15 & 12 \\
Senegal & 42.1 & 58 & 33 & 0 \\
\hline
\end{tabular}

Economic Consulting Associates (2009) [2]. 
supplied has to meet real-time needs, but, on annual averages, the electricity distributed has to comply with the agreed quotas [5].

\section{Relevance}

The project relevance was highly satisfactory. The project objectives were well aligned with national and regional development priorities which attached great importance to securing more energy supply to support economic growth.

National development priorities. At the time the project was conceived, the power sectors of the three countries were faced with the serious need for reliable, low-cost power supply and increased electricity access in urban and rural areas. The three countries had low supply and high cost of electricity coupled with low electrification rate. The main problems identified in the project appraisal report remain valid today and have even worsened. While Mali and Mauritania have periodic generation deficits, blackouts are chronic in Senegal. Given the increasing cost of hydrocarbons, the electricity generated at Manantali has been providing a substantially lowercost alternative to thermal-based power generation and also respond to the need to develop more clean sources of energy with limited greenhouse emissions. Besides that, there was also the need to meet debt service associated with the building of the Manantali dam [7].

Regional development priorities. The investment required to realize the Manantali hydropower project was beyond national capacities, both in technical and financial terms. The regional approach proved to be the most adequate, as it created a regional common good through shared water management, avoided possible resource con- flicts and laid down the basic infrastructure for establishing a sub-regional energy market. In retrospective, the project also aligns with and anticipates the long-standing regional aspirations of the Economic Community for West African States (ECOWAS) which Senegal and Mali belong to, and of the Western African Power Pool Organisation (WAPP), that aim at creating a regionally interconnected electricity market [3].

\section{Design Quality}

Quality at entry is satisfactory. The project was backed by feasibility studies which demonstrated its relevance and viability and was built upon an equitable and consensual distribution of costs and benefits amongst the three countries. Overall the project underwent adequate screening relating to the technological and institutional options, which were based on a joint donor appraisal mission undertaken in 1996 [4]. However, a number of relevant technical and institutional limitations, which are undermining the project's sustainability, have gradually emerged.

Institutional issues. Given the project dimension and strategic relevance, donors requested important reform of the OMVS organisational framework, which brought about the establishment of SOGEM. At the same time, to improve the performance of the regional energy market and of the national electricity companies, energy sector restructuring was also part of donor's conditions. However, the privatization process, led by the World Bank, failed in all three countries given the limited size and fragmentation of the national energy markets and the lack of interest from international investors.

Financial issues. No effective mechanisms were put in place to guarantee regular payments from national electricity companies and no credible sanction mechanism was devised for defaulter parties. As a consequence, the payments due according to the agreed Tariff Protocol have not always been forthcoming and payment arrears reached nearly FCFA 45 billion at the end of December 2007 [8]. In addition to that, funds for maintenance and upgrading of the hydroelectric plant and transmission lines (Main Equipment Rehabilitation Fund) were not set aside by SOGEM as originally planned and agreed. The same happened to the Hydrology Risk Fund (15 billion FCFA) that SOGEM was supposed to set up to ensure that payment obligations are met in the event of a disaster or a poor rainfall year. Although all governments accepted in principle that power could have been cut off in case of defaults in payments, SOGEM and EEM have never been able to implement this clause. The situation improved only in 2009, when a resolution (470) from the OMVS Council of Ministers called upon member countries to ensure the regular payments of the electricity bills and authorized EEM to cut electricity supply to the defaulting electricity companies. The sanction mechanism worked well, given that, according to the Annual EEM technical report released in March 2011, the recovery rate of new bills was up to $100 \%$ (Eskom, 2003-2010) [9]. As for the old arrears, a World Bank source reports that $75 \%$ of the outstanding 2007 total arrears were settled at the end of April 2009 [8].

Management contract issues. The concession agreement, which regulates all aspects of energy production, transmission and purchasing at Manantali plant, has left some important issues unclear that led to disagreements 
between SOGEM and EEM over contractual obligations and eventually to an anticipated termination of the 15-year contract. This was due to divergent interpretations over responsibilities for the necessary maintenance works and the revision of EEM remuneration, which is based on a tariff determined by SOGEM indexed to the inflation rate of the three countries. Although the two companies went for an amicable settlement of the dispute, they were not able to reach an agreement over key contractual issues and mutually agreed upon an anticipated termination of the concession agreement by the end of October 2011 with the possibility to extend the contract until June 30, 2012 [9]. As of September 2011, no new operator had been recruited, which led to a new extension of EEM contract. In this respect it is also important to notice that the contract between EEM and the three national utilities had yet to be signed. The contract was closed at the end of July 2014 after successive extensions. While waiting for the recruitment of a new private operator, a new company, La Société d'exploitation de Manantali et de Félou or SEMAF was set up. The first meeting of its board members took place on the $14^{\text {th }}$ July 2014 in Bamako.

Technical issues. The electricity grid of the OVMS system has two important limitations. First of all, there is a problem of security of supply on the Western line, given that an upstream line breakdown cuts off energy supply to Mauritania and Senegal. Secondly, while the energy generated by the upcoming Felou hydroelectric project (between 300 and $350 \mathrm{GWh}$ ) can transit on the existing power grids, there is no enough transport capacity for other power generation projects. Some interviewees pointed to its technical limitations with respect to the development potential of a regional energy market. By contrast, others reported that the current size of the three countries' energy market still provides very limited possibilities for trading electricity surpluses across borders.

\section{Effectiveness}

The overall project effectiveness is rated satisfactory. In the three countries there is a strong consensus on the project's positive outcomes. However, while the achievement of the planned project's physical outputs has been satisfactorily fulfilled, broader development outcomes remain only partially achieved.

\subsection{The Project's Outputs}

Physical outputs. As originally planned, physical works for the hydropower plant and the two transmission lines were completed. The transmission system from Manantali consisted of an Eastern System toward Bamako and a Western System toward Dakar and Nouakchott. Eleven substations were established at various locations along the Senegal River, along with a dispatching center in Manantali and a high voltage control building. Beside the power station and transmission lines, an optical fiber cable linking the Manantali power plant to all the high voltage stations was installed to allow proper functioning of the System Control and Data Acquisition (SCADA) system and the telecommunications system [7].

Technical performance. From a technical perspective, the hydropower station worked well. The 194 MW operational installed capacity from Manantali was allocated according to the agreed quotas, namely: $104 \mathrm{MW}$ to Mali, 60 MW to Senegal and 30 MW to Mauritania [2]. With an average annual production of $802 \mathrm{GWh}$ over the period 2003 to 2010, the contribution of Manantali to the OMVS countries has been significant, especially in the case of Mali (Figure 2). It was only between 2006 and 2007 that Manantali hydropower generation was sig-

(a)

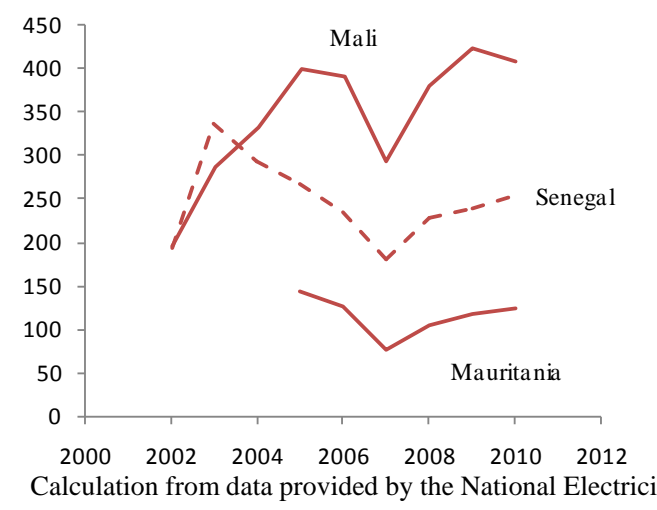

(b)

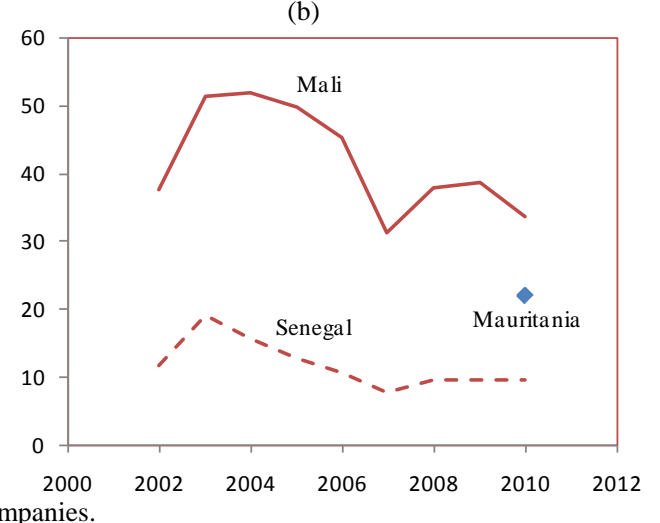

Figure 2. Contribution of Manantali to the three countries’ energy production. (a) GWh; (b) Percentage. 
nificantly reduced to $600 \mathrm{GWh}$ due to insufficient rainfall that led to more severe energy crisis in the three countries. The diminishing contribution of Manantali to the countries' energy production from 2005 to 2010 is due to the increasing contribution of new thermal-based electricity generation. As an example, in Senegal the contribution of the Manantali power plant to the national electricity generation capacity decreased from 11.69\% in 2002 to $9.68 \%$ in 2010 .

The existing HV power grids, that have a $1300 \mathrm{~km}$ extension, is the backbone for a future regional interconnected network and offer the possibility to linking Western Africa's power system with those of Maghreb through Mauritania.

Socio-environmental outputs. With regard to the PASIE component, the most remarkable achievement has been the approval of the Water Charter in 2002 that addresses the issue of efficient allocation of water amongst different purposes including agriculture, electricity and navigation. However, under this component little evidence on the project outputs could have been collected given that no final completion report was submitted by OMVS. This component has not been sufficiently robust to address the enormous environmental and health effects related to the construction of Manantali and Diama dams. Problems related to typha proliferation persist, albeit some countries have been more effective in addressing this problem. For instance, stakeholders' interviews showed that agricultural production was more seriously endangered in Mauritania than in Senegal where funds were made available to execute mechanical treatment in the irrigation canals obstructed by the typha [10].

\subsection{The Project's Outcomes}

Achievement of the project outcomes, as originally planned, has been satisfactory (Table 2). Major concerns are due to the risk factors that undermine the sustainability of these achievements. The positive impact of the project dilutes today in the face of an increasing demand for electricity in the tree countries. Restructuring of OMVS member countries' energy sector and the implementation of the so-called OMVS 2nd generation projects, are instrumental to meet the expectations of users (i.e. improving service quality, lower cost of electricity, and increased access in rural areas) and support overall economic growth.

Other interventions, for which a national approach was deemed more appropriate, such as the development of irrigated agriculture, restructuring of the national energy sectors and rural electrification, were left at the country level. However, in these areas progress has been slower to materialize because of lack of domestic financing and

Table 2. Summary of project achievements in relation to the planned outcomes.

\begin{tabular}{|c|c|}
\hline Project outcomes & Achievements \\
\hline $\begin{array}{l}\text { Reduce the long-term cost of electricity } \\
\text { supply to the three countries. }\end{array}$ & $\begin{array}{l}\text { Achieved, but depends upon the future generation mix between } \\
\text { new hydropower facilities and thermal power plants. }\end{array}$ \\
\hline $\begin{array}{l}\text { Meet debt service associated with the } \\
\text { construction of Manantali dam. }\end{array}$ & $\begin{array}{l}\text { Achieved, but long term sustainability at risk depending on the } \\
\text { financial viability of public utilities. }\end{array}$ \\
\hline $\begin{array}{l}\text { Increase the efficiency and reliability of } \\
\text { the power systems in the three countries. }\end{array}$ & $\begin{array}{l}\text { Achieved. Manantali significantly contributed to power generation } \\
\text { capacity of the three countries, but serious electricity production } \\
\text { deficits persist due to an increasing demand. }\end{array}$ \\
\hline $\begin{array}{l}\text { Establish an effective organization to construct and } \\
\text { operate the project facilities and to mitigate environment } \\
\text { and health impacts of the Manantali dam. }\end{array}$ & $\begin{array}{l}\text { Partially achieved through the establishment of SOGEM and rolling } \\
\text { out of OMVS mitigation programmes. However, most problems related } \\
\text { to the increase of water-borne diseases are still to be addressed. }\end{array}$ \\
\hline $\begin{array}{l}\text { Promote competitive private sector participation in } \\
\text { project operation and in financing of future } \\
\text { generation projects in the Senegal River Basin. }\end{array}$ & $\begin{array}{l}\text { Partially achieved through involvement of ESKOM. However, private } \\
\text { sector participation in financing of future power generation projects } \\
\text { is deemed difficult because of the lack of experienced and truly } \\
\text { independent national regulatory authorities coupled with the small } \\
\text { size and fragmentation of the regional energy market. }\end{array}$ \\
\hline $\begin{array}{l}\text { Support the traditional agricultural sector downstream } \\
\text { through rational management of Manantali reservoir. }\end{array}$ & $\begin{array}{l}\text { Partially achieved. The Water Charter addresses the issue of efficient } \\
\text { allocation of water amongst different purposes including agriculture. } \\
\text { OMVS reported that releases were adequate to support irrigated } \\
\text { agriculture in a period of normal rain fall. However, local administrators } \\
\text { along the River Senegal irrigated areas complained that flood releases } \\
\text { were insufficient to support recessional agriculture. }\end{array}$ \\
\hline
\end{tabular}


insufficient political support. In particular, in the agriculture sector the full irrigation potential of the Senegal River has not been exploited yet [11].

Impact on the living conditions of the riverine population. The project was expected to provide electricity to low-income rural communities and productive activities to the riparian populations. However, no rural electrification programme was originally included. Nevertheless, the project has generated a potential demand in rural population living nearby the transmission lines. This demand has been only partially met, as in the case of the electrification of the villages of Manantali and Boufalabé. Economic activities have prospered around the project site in Manantali, where a community of relatively well-paid employees fuelled new commercial and agricultural activities [11]. See Box 3 for an example of impacts.

Institutional learning. The successful cooperation between the OMVS countries has been an example for other regional organizations. Today, Manantali is an operational model that the WAPP is seeking to promote elsewhere in Western Africa [3]. Along the Manantali example, other regional hydroelectric projects are currently planned by the OMVS, such as the Gouina Hydroelectric project and the Koukoutamba multipurpose dam project [12]. In parallel, with the OMVS initiatives, hydropower projects are being planned in Guinea and Senegal by the OMVG (Organisation pour la Mise en Valeur du Fleuve Gambie). In addition, the institutional and organizational framework developed for implementing the project's socio-environmental component, which is based upon a community-based approach, was useful to implementing other similar projects, such as the PGIRE.

Regional integration. So far, collaboration amongst the three countries has been limited to the energy and water sector. At the institutional level, there has been tangible strengthening of collaboration between the three energy utilities thanks to the establishment of a formal framework (CTPI and CDI) for regularly discussing common energy matters [5]. The three OMVS countries also manifested their interest for elaborating a common energy policy. Harmonization of energy policies is a potential factor for enhanced regional integration. Yet, some important institutional obstacles persist. For instance, both Mali and Senegal are members of the ECOWAS and of the WAAP Secretariat, while Mauritania is not involved in these organizations and is more keen to secure energy connection with Northern Africa countries.

With respect to the creation of a sub-regional energy market results have sometime been overstated. Given the structural deficit in power generation in the three countries, the existing interconnection cannot yet been applied to a real electricity trade. Cross-border electricity trade occurs occasionally.

Capacity building. Capacity building was an important criterion for the selection of the private operator. The mission noted the high degree of competence and dedication of the technical staff posted at Manantali. Most staff benefited from training programmes and technological transfer from ESKOM expatriate personnel. At present, among EEM's experts, only the General Manager is a Southern African expatriate; the rest are from OMVS member countries and are able to autonomously manage the maintenance operations.

Unintended positive impact. The Manantali project also had an unintended positive impact on the telecommunication sector of the three countries, which have the possibility to establish a sub-regional digital interconnected system thanks to the telecommunication equipment that were installed for transmission operations of the OMVS Interconnected Network (World Bank, 2006) [1]. So far, the installation of the fiber optics provided opportunities for improving national telecommunication systems, especially in Mauritania.

\section{Efficiency}

The efficiency of the project is satisfactory. In spite of the complexity of the project, it was implemented within the planned budget and work plan.

Financial and economic performance. Various evaluations [1] [5] [11] of the financial and economic viability of the Manantali hydropower project concluded that the project would have yielded an acceptable economic rate of return (Table 3), which would be even higher today given the increased costs of alternative source of elec-

\section{Box 3. An example of the impacts of Manantali electricity at the micro level.}

In Mauritania, the electricity produced by Manantali has been recently used for land irrigation and contributed to reduce operating costs. For example, data from a Cooperative Union shows that electricity prices in 2010/2011, when Mananatali electricity was made available, were $38 \%$ lower than the price paid for thermal electricity. For the 2008/2009 harvest, the total cost of diesel was 27.4 billion of Ouguiya against 17.0 billion of Ouguiya for the 2010/2011 harvest. Union Coopératives Agricoles; Projet Pilote Gorgol II, KAED. 
Table 3. Indicators of financial and economic performance (\%).

\begin{tabular}{ccc}
\hline & Ex-ante (2000) & Ex-post (2007) \\
\hline Financial return on investment & Not available & 7 \\
Economic rate of return & 15,6 & 15,9 \\
\hline
\end{tabular}

AfDB (2007), Manantali_-Project Appraisal Report 2000, and AfDB, Manantali_Project Completion Report [4].

tricity. The project cost effectiveness can be assessed by considering that, in Senegal between 2005-2010, the average electricity production cost from Manantali was 33.5 FCFA/Kwh, whereas the average production cost of electricity generated in thermal plants was 47 FCFA/Kwh [1]. In addition to that, the project had positive effects on reducing greenhouse gas emission that would have been generated by other more pollutant sources of electricity.

Nevertheless, it should be considered that the positive effects on the national average electricity production costs has been reduced by an increasing demand of electricity that was met through more thermal-based electricity.

Project management. In spite of its low experience, SOGEM successfully managed to complete the project within the agreed terms. As far as the component financed by the AfDB is concerned, the following can be noted. Activities were completed within the planned works schedule, whereas delays due to untimely fund availability were redressed by streamlining specific tender procedures. As compared to other project components, there were no delays associated to poor project design, but rather to the inexperience of SOGEM in dealing with international tender procedures. In this respect, proactive interventions of the AfDB task manager proved to be instrumental to avoid more serious calendar slippages.

At the time the AfDB project completion report was submitted, the disbursement rate for the ADF loan and grant were $92.44 \%$ and $54 \%$ respectively. The low rate of disbursement of the grant component was due to the partial execution of the project's socio-environmental component. The project component financed by the Bank did not incur cost overrun [4].

Donor coordination. To coordinate the many donors involved, the AfD, KfW and the World Bank put in place a coordination committee, which was SOGEM's reference point. Annual donor meetings were also held to facilitate project implementation and fix problems with contractors [4]. However, SOGEM reported that differences in procurement, financing and disbursing procedures, rules of origin for supply contracts and in payment processes, added an important administrative burden to its staff. In addition, in several occasions, people interviewed expressed concerns about the lack of transparency and coordination of donor evaluation process and for the lack of a common platform for project monitoring.

\section{Sustainability of Results}

The project sustainability is at risk given a number of technical, financial and institutional considerations that put at risk the project's development outcomes.

Technical issues. The continuing deterioration of the medium voltage national distribution networks generates power interruption of such magnitude that the distribution of the energy delivered by Manantali as annually planned is highly threatened. Such a situation doesn't help manage the existing country quota system and inevitably leads to the loss of bonus for the private operator that already proved to be a source of tension between SOGEM and EEM [9].

At the time the AfDB's project completion report was prepared (2007), several concerns were raised in relation to the delayed establishment of the Main Equipment Rehabilitation Fund by SOGEM and insufficient maintenance works undertaken by the private operator, which was also supposed to set aside resources for major maintenance works (Fonds de Grandes Révisions) [1]. The report noted that the lack of necessary spare parts and the insufficient implementation of safety measures to protect generation and transmission facilities undermined the technical sustainability of the project. Since then, and as a result of an internal agreement between EEM and SOGEM, the situation has sensibly improved. Both parties agreed upon implementing a maintenance emergency plan (Plan d'Actions Prioritaires) and works are being executed as planned [13].

The competence of the private operator and the level of skills achieved by the personnel working on the dam operations have thus far ensured the good functioning of the power plant and dispatching services. However, the 
uncertain environment, in which EEM personnel has to work till a new private operator is selected, can be detrimental to the project.

Financial issues. Repayments of donor loans were envisaged through a debt service portion of the revenues generated by energy supply to the national electricity companies. Thus far, in view of the national electricity companies' performance, it is not possible to predict the sustainability of the project. While the problem of payment arrears to SOGEM has been temporarily fixed, the long-term project financial sustainability depends on the success of the restructuring effort of the incumbent utilities and their improved ability to cover operating costs. Another relevant threat to the project financial sustainability is posed by the misuse of SOGEM funds that have been used several times beyond debt service [11]. For example, under political pressure, SOGEM engaged in rural electrification projects, which should have been executed by national authorities, and in 2007 contracted out energy supply to compensate for production losses in Manantali.

Institutional arrangement issues. The institutional arrangements that govern the OMVS and its entities proved to be resilient to dramatic and turbulent political changes, such as two military coups in Mauritania. This is due to the solid domestic awareness about the beneficial impact of the project and its strategic nature for the economic development of the involved countries. Nevertheless, there are some weaknesses in the existing project governance structure. Manantali management contract provisions, as well as some loan conditions, such as the establishment of two Risk Funds, were repeatedly violated. The situation was so serious that EEM senior managers considered that donors should intervene to help solve the problem. More importantly, interviewees pointed at the weaknesses of the mechanisms that should isolate the project environment from political interference and ensure contract enforcement.

Potential conflicts on water usages. In principle, efficient water management is regulated by the 2002 Water Charter. However, the establishment of the Hydrology Risk Fund is of paramount importance to compensate years of poor rainfall such as 2007. Peasants also complained that flood releases are insufficient to support recessional agriculture and that electricity generation is the only government priority [14]. Actually, the full irrigation potential of the Senegal River has not been yet achieved because of delays in putting in place the necessary infrastructure at national level [11].

\section{Conclusions}

Manantali energy project is a successful project which delivered expected results of producing electricity at low cost and from a clean source. The contribution of the project to the energy sector of the three countries is however limited given the huge and still increasing demand of energy because of the rapid urbanization and demographic growth. The project is facing sustainability problem stemming from political interference, the conflicting interpretation of respective obligations of SOGEM and ESKOM, and the lack of regional sector regulation in relation to contract enforcement and conflict arbitration.

Success factors. The project was conceived within a sound regional collaboration framework, well-grounded on international conventions and on a clear distribution of costs and benefits amongst the participating countries. The selection of a rigorous methodology and process by which the three OMVS countries allocated the costs and benefits of water usage had important implications. It helped define the financial terms and structure (e.g. debt service, electricity quotas) of past and future projects and made evident that regional cooperation was necessary to realize benefits for all member countries that could not have been reached individually. In the three countries, there is high domestic consensus on the benefits the project brought about and great expectations about realization of future projects. Political willingness and long-term commitment at the highest governmental level have been key to the successful implementation of the project and to adopt necessary corrective measures to ensure the project's technical and financial sustainability. As a result, the project already sound financial and institutional framework was integrated with a credible sanction mechanism for defaulter parties.

Risk factors. The pressing need to recruit a foreigner operator to act as an independent arbitrator, is the most tangible evidence of the governance problems the project is confronted with. Mechanisms that should isolate the project environment from political interference and ensure management contract enforcement are weak. Fulfillment of some loan conditions is also weak and apparently not adequately monitored by donors.

Role of national governments. Domestic distribution of the project benefits depends upon national complementary policies. Coherent national policies are needed not only to ensure the sustainability of the project outcomes, but also to mutually reinforce the benefits that the project delivered. 
Donors' role. Donor coordination with respect to project design and implementation has been key to success. However, SOGEM reported that harmonization of donor procedures upstream would have smoothed project implementation. After project's completion, donors have not proactively collaborated in subsequently enforcing the agreed loan conditions, especially in relation to SOGEM and the national electricity companies' misconducts. In addition, insufficient efforts have been devoted to ensure the full compliance by the OMVS countries of their commitments in terms of the continued efforts of restructuring the energy sector and preparation of an integrated control against the prevalence of waterborne diseases that still affect the riparian populations. Some donors, including the AfDB, have been little involved in establishing a policy dialogue on energy sector reform with member countries.

Socio-environmental issues. This is apparently the weakest project component in terms of activities carried out and outcomes delivered. Poor systematic monitoring and collection of national data by the OMVS make an evidence-base assessment of the objectives achieved impossible.

\section{Policy Implications}

Five main lessons for effective support of regional operations can be drawn from the present case study:

1) A set of common development priorities is necessary for forging shared interests and sustainable project outcomes in countries participating in multinational operations. This needs to be complemented with a rigorous methodology for cost and benefit sharing geared towards achieving an equitable distribution of project outcomes and get participating countries' continuous consensus and commitment.

2) Effective and binding institutional arrangements are of paramount importance if multinational operations are to succeed. Agreed rules have to be effectively and timely enforced through political decisions of the governments of all participating countries. In the absence of independent regional regulatory authorities, concessions or management contracts have to be even clearer.

3) To ensure a more equitable distribution of benefits of large regional hydroelectric projects, complementary national policies to develop irrigated agriculture, develop rural electrification and manage conflictive water needs across different users need to be designed and timely implemented. National funds should be made available for developing adequate national transmission lines to ensure real-time supply of electricity.

4) In regional infrastructure projects, donors' coordination should not be limited to the co-financing agreements and the setting up of project implementation structures. It has also to consider reforming/adapting the national regulatory, planning and institutional framework in a way to sustain the project and furthering its impact on the target population.

5) To ensure that local populations benefit from regional infrastructure projects, their socio-environmental components should be periodically monitored, including systematic assessment of the status and perceptions of the affected populations.

\section{Acknowledgements}

This paper has benefited from: 1) the competent contribution of Ousmane Tanou Diallo, a West African Energy expert; 2) very useful comments of Tesfaye Dinka, John Eriksson, and Fredrik Söderbaum, external peer reviewers; and 3) comments of anonymous referees. The findings, interpretations, and conclusions presented in this paper are the sole responsibility of the authors.

\section{References}

[1] World Bank (2006) Overview of Regional Energy Projects and Project Performance Assessment Report for the Mali, Mauritania and Senegal Regional Hydropower Development Project (Credits 270, 2971 and 2972). Independent Evaluation Group, World Bank, Washington DC.

[2] Economic Consulting Associates (2009) The Potential of Regional Power Sector Integration, Manantali Generation Case Study. Economic Consulting Associates, London.

[3] AfDB (2011) Energy and Power Infrastructure to Facilitate Regional Integration in the ECOWAS Region. Background Study for the African Development Bank’s Regional Integration Strategy Paper for the ECOWAS Region. AfDB, Abidjan, Ivory Coast.

[4] AfDB (2007) Multinational OMVS: Rapport d'achèvement de Manantali, non présenté au Board. AfDB, Abidjan, Ivory Coast. 
[5] JBCI (2008) Aid Effectiveness to Infrastructure: A Comparative Study of East Asia and Sub-Saharan Africa-Senegal Case Study.

[6] Winston, Y.H. (2011) Benefit Sharing in International Rivers: Findings from the Senegal River Basin, the Columbia River Basin, and the Lesotho Highlands Water Project. The World Bank, Africa Region Sustainable Development Department.

[7] World Bank (2005) Implementation Completion Report (Ida-29720) on a Credit in the Amount of Sdr 7.7 Million (US\$10.5 Million Equivalent) to the Republic of Senegal for a Regional Hydropower Development Project, January 7. World Bank, Washington DC.

[8] World Bank (2009) Additional Financing for the Felou Hydroelectric Project of the West Africa Power Pool (APL) Program. World Bank, Washington DC.

[9] ESKOM (2003-2010) Compte Rendu Technique Annuel—2003 to 2010. ESKOM, Sunninghill.

[10] Agence Française de Développement (2008) Evaluation rétrospective du volet environnemental et social du barrage de Manantali. Série Evaluation et Capitalisation Ex Post, No. 15.

[11] Banque allemande de développement (KfW), Banque européenne d'investissement and Agence Française de Développement (2009) Le Barrage de Manantali, rapport de synthèse. Coopération financière avec l’Organisation pour la mise en valeur du fleuve Sénégal (OMVS).

[12] OMVS (2007) Fiches des projets de la deuxième génération. A mettre à jour.

[13] SOGEM (2011) Situation Technique et Financière des Travaux du Plan d'actions Prioritaires—Rapport de Synthèse.

[14] Gautron, J.C. (1967) L’aménagement du bassin du fleuve Sénégal. Annuaire Français de Droit International, 13, 690702. 